\title{
EVOLUCIÓN EN LA NOCIÓN DE RIESGO ASEGURABLE Y NUEVOS MERCADOS: EFECTOS Y DESAFÍOS PARA LA INDUSTRIA ASEGURADORA DESDE UNA APROXIMACIÓN PRÁCTICA ${ }^{*}$
}

\section{EVOLUTION IN THE NOTION OF INSURABLE RISK AND NEW MARKETS: EFFECTS AND CHALLENGES FOR THE INSURANCE INDUSTRY FROM A PRACTICAL APPROACH}

\author{
VICENTE RÍOS URZÚA ** \\ Fecha de recepción: 30 de abril de 2018 \\ Fecha de aceptación 24 junio de 2018 \\ Disponible en línea: 15 de marzo de 2019 \\ Para citar este artículo/To cite this article
}

Rios Urzua, Vicente, Evolución en la noción de Riesgo Asegurable y Nuevos Mercados: efectos y desafios para la industria Aseguradora desde una aproximación práctica, 49 Rev.Ibero-Latinoam.Seguros, 133-160 (2018). https://doi.org/10.11144/ Javeriana.ris49.enradoi:10.11144/Javeriana.ris49.enra

* Artículo de reflexión desarrollado con miras a aportar una visión panorámica respecto de los efectos prácticos de aceptar una visión dinámica de riesgo y cómo eso influye en las técnicas de cumplimiento de las cargas o deberes que los contratantes de un seguro poseen, particularmente desde una visión precontractual.

** Abogado, Licenciado en Ciencias Jurídicas y Sociales, Universidad Adolfo Ibáñez (Chile). Master in Business Law, LL.M.(C) UAI. Diplomado en Derecho Administrativo mención Derecho Económico, Universidad Católica de Chile (PUC). Orcid: 0000-0002-8655-4607. Miembro de la Asociación Internacional de Derecho de Seguros (AIDA) - Sección Chilena. Legal \& Insurance Manager, Liventus S.A. Contacto: vrios@liventusglobal.com / v.riosurzua@gmail.com. 


\section{RESUMEN}

La fuerte diversificación de mercados potenciales a implicado en los últimos años un importante incremento en el volumen de transacciones y, como consecuencia, la necesidad de lograr un mejor y más profundo conocimiento de cada una de las industrias tomadoras tradicionales. En este sentido, los esfuerzos se han centrado en mejorar la conceptualización de ocurrencias transferibles, lo que ha devenido en nuevas categorías de riesgos asegurables, pero siempre en un contexto mayoritariamente comercial en términos de respuestas taylor made, lo que para el resto de la industria se traduce en esfuerzos regulatorios, normativos y contractuales que muchas veces no generan reacciones oportunas respecto de las expectativas del mercado. En este escenario, cobra valor contar con una visión dinámica de riesgo asegurable, lo que permite ex ante internalizar condiciones que pueden apoyar la automatización en la suscripción de riesgos atípicos como si fueran riesgos tradicionales.

Palabras clave: riesgo asegurable; nuevas industrias; transferencia; deberes precontractuales; riesgos atípicos. 


\begin{abstract}
The strong diversification of potential markets has implied in recent years a significant increase in the volume of transactions and, as a consequence, the need to achieve a better and deeper knowledge of each of the traditional industries. In this sense, efforts have focused on improving the conceptualization of transferable occurrences, which has resulted in new categories of insurable risks, but always in a mostly commercial context in terms of taylor made responses, which for the rest of the industry it translates into regulatory, normative and contractual efforts that often do not generate timely reactions with respect to market expectations. In this scenario, it is valuable to have a dynamic vision of insurable risk, which allows ex ante to internalize conditions that can support automation in underwriting atypical risks as if they were traditional risks.
\end{abstract}

Palabras clave: riesgo asegurable; nuevas industrias; transferencia; deberes precontractuales; riesgos atípicos.

\title{
SUMARIO
}

INTRODUCCIÓN - 1. INDUSTRIA ASEGURADORA REGIONAL: CIFRAS DEL CRECIMIENTO - 2. NUEVA PERSPECTIVA DE ANÁLISIS DE RIESGO ASEGURABLE: UNA OPORTUNIDAD DINÁMICA PARA EL MERCADO ASEGURADOR - 2.1. Desde la suscripción de riesgos - 2.2. Desde la administración de siniestros - 2.3. El asegurado como consumidor: el caso chileno - 3. APROXIMACIÓN PRÁCTICA: LA AGROINDUSTRIA Y EL TRANSPORTE - 4. PERSPECTIVAS REGULATORIAS PARA OBTENER VENTAJAS DE LAS OPORTUNIDADES - CONCLUSIONES - BIBLIOGRAFÍA. 



\section{INTRODUCCIÓN}

Un Asegurado potencial (o tomador de seguros) entiende que estimar, definir o describir una probabilidad de pérdida en términos de riesgos será lo que finalmente fundamentará la decisión de internalizar o no su gestión. En este sentido, una correcta categorización, previo a la toma de esta esencial decisión, implicará tener presente que el mercado Asegurador, por cuestiones económicas o intereses distintos de los técnico-preventivos que motivan la decisión del Asegurado, puede proponer pólizas con estructuras de cobertura que no necesariamente aborden toda la dimensión del riesgo que la industria del Asegurado produce.

En términos generales, buscar darle contenido al actual Art. 513 inciso segundo del Código de Comercio de Chile o a sus equivalentes en las legislaciones comparadas que buscan conceptualizar la noción de Riesgo Asegurable no resulta un esfuerzo inoficioso, dado que justamente lo que las partes contratantes de un seguro entiendan como riesgo asegurable será lo que finalmente circunscriba los esfuerzos indemnizatorios en caso de siniestro, entre otros efectos que regularán la relación Asegurado-Asegurador.

Podemos afirmar que actualmente la Industria Aseguradora vive un proceso de evolución que viene dado no sólo por la aplicación de nuevas tecnologías a los modelos de negocios, sino también por la creciente especialidad de las Gerencias de Riesgos y la continua sofisticación de las metodologías de identificación, análisis y tratamiento de riesgos, lo que se ha traducido en múltiples acciones preventivas, que emanan desde la misma industria (Asegurados, Aseguradores, corredores de seguros, consultores, etc.) y que vienen a apoyar las labores propias de los departamentos de suscripción. Lo dicho se traduce en nuevas formas de analizar riesgos tradicionales o conocidos, además de surgir nuevas contingencias en fases productivas o de generación de valor que muy probablemente la industria Aseguradora no había percibido antes.

Lo indicado deviene, a priori, en mayores oportunidades de crecimiento para la industria Aseguradora, pero también en mayores deberes de diligencia. En este sentido, el presente trabajo busca hacer notar cómo influye desde el punto de vista de las cargas o deberes de los agentes 
contratantes de un seguro la existencia de nuevos riesgos en industrias tradicionales y no tradicionales, y qué técnicas podrían aplicar estos agentes para buscar asegurar el cumplimiento de estos deberes.

\section{INDUSTRIA ASEGURADORA REGIONAL: CIFRAS DEL CRECIMIENTO}

A diciembre del 2017, 19 compañías de seguros generales chilenas (considerando las nacionales y extranjeras con participación en el mercado local) presentaban variaciones positivas en términos de aumentos en primas directas transadas, esto implica que un 70\% de la industria mostró números positivos de crecimiento en comparación a su último año, esto sin considerar al menos 5 nuevos actores en el mercado quienes no cuentan con números del año 2016 para realizar la comparación

En Colombia, un importante referente para la industria en Sudamérica, la situación es muy similar. Podemos afirmar que serían casi 10 años de crecimiento continuo con variaciones positivas de entre el $3 \%$ y el $10 \%$ en totales anuales de primas transadas, tomando como referencia el último año de cierre estudiado por la industria (2017)로.

El 2015 México presentó cifras de crecimiento históricas, las que casi triplicaron lo que avanzó el PIB del país en el mismo periodo ${ }^{3}$, y esto no es muy distinto en los demás países de la región.

Si uno quisiera buscar respuestas podríamos encontrar múltiples líneas de análisis, pero en nuestra opinión son dos los elementos que cobran especial relevancia desde el punto de vista de la explicación inmediata.

1 Estadísticas públicas. Comisión para el Mercado Financiero, ex Superintendencia de Valores y Seguros. Archivo on-line disponible en: http://www.svs.cl/p ortal/estadis ticas/606/articles-24894_ recurso_1.pdf. Última visita: 07 de agosto de 2018.

2 Estadísticas públicas. Federación de Aseguradores Colombianos. Archivo on-line disponible en: http://www.fase colda.com/file s/2915/1975/0 920/Cifras_diciembre_2017.pdf. Última visita: 07 de agosto de 2018 .

3 Prensa especializada de la época cifraba en 7,4\% el crecimiento real del sector asegurador, sobre el $2,5 \%$ de crecimiento del PIB para el mismo periodo. Estadísticas publicadas el 24 de febrero de 2016, medio de circulación nacional El Economista. Versión on-line: https:/www.ele conomista. com.mx/ sect orfinanciero/ Sector-asegu rador-crece -tres-veces-m as-que- el-PIB — 201 60224-0132.h tml. 
En primer término, la tecnología a disposición del análisis de riesgos y suscripción de seguros a impactado la forma en que la industria Aseguradora gestiona su modelo de negocios. Esto redunda en que hoy existan mecanismos de cuantificación económica de ocurrencias o siniestros mucho más sofisticados que antaño y, basado en esto, mecanismos de distribución y retención de primas mucho más ajustados a lo real, elemento que finalmente ha devenido en un aumento en la cantidad de transacciones, mayor volumen de potenciales tomadores de seguros y menor costo directo de prima a retener.

En segundo lugar, derivado de la nueva tecnología disponible, se han generado mejores herramientas de valoración de riesgos, lo que ha permitido profundizar y diversificar la oferta de productos en industrias tradicionales que, desde una perspectiva de análisis técnico, han demostrado poseer riesgos de diversa naturaleza y, por ende, de distinto interés desde el punto de vista del mecanismo de transferencia a seleccionar.

Evidentemente existen otros elementos que expliquen de manera más completa y suficiente el crecimiento continuo que la Industria Aseguradora ha presentado, particularmente desde el punto de vista de los macro-ciclos económicos o incluso desde la conceptualización de los Seguros como elemento relevante en las cadenas de valor de las industrias aseguradas. Sin embargo, es la tecnología y cómo ello a influido en la generación de nuevas herramientas de delimitación de riesgos transferibles lo que, en lo inmediato, se presenta como una justificación asociada al cambio en los paradigmas tradicionales del mercado Asegurador que muy probablemente tenga nexo causal directo con el crecimiento que esta industria mantiene.

En lo sucesivo, presentaremos líneas respecto de cómo esta evolución implica no sólo crecimiento, sino necesarias adaptaciones desde tres perspectivas funcionales del seguro (desde la fase de suscripción, desde la fase de administración o gestión de siniestros y desde la relación de consumo existente en la contratación de un seguro) y cómo la internalización de una noción dinámica de riesgo y la conceptualización precontractual de ciertos deberes operan como mecanismos relevantes para asegurar la eficiencia (legal, administrativa y regulatoria) que la industria reclama. 


\section{NUEVA PERSPECTIVA DE ANÁLISIS DE RIESGO ASEGURABLE: UNA OPORTUNIDAD DINÁMICA PARA EL MERCADO ASEGURADOR}

Los deberes de correcta individualización, delimitación y no agravación que circunscriben la noción de riesgo devienen naturalmente en generar estrategias que permitan una mejor aproximación al concepto. Desde este punto de vista, la doctrina y práctica comercial se han centrado en generar clasificaciones con vocación generalista que permitan, en base a características básicas, aportar nociones descriptivas que faciliten la toma de decisiones del mercado Asegurador respecto a la asegurabilidad o no de un determinado riesgo.

Si pudiéramos tomar los elementos descriptivos generales, debiésemos afirmar que un Riesgo Asegurable es aquel que:

a. Debe constituir un Peligro o amenaza.

b. En términos de ocurrencia, debe ser un riesgo posible.

c. Conocido o describible en su contenido o extensión.

d. No imputable a dolo del Asegurado: Es un elemento ex post, pero desde el punto de vista casuístico-profesional del suscriptor, debe ser un elemento analizable ex ante.

En base a lo anterior, encontramos clasificaciones de diverso origen, como por ejemplo aquella de origen legal que encuentra su fuente normativa en los Artículos 530, 549 y 551 del Código de Comercio de Chile, que nos permite distinguir entre aquellos riesgos que corresponden naturalmente al Asegurador, aquellos por los que responde sólo en caso de mención expresa y aquellos por los que derechamente no responde ${ }^{4}$.

Otras clasificaciones esencialmente jurídicas nos permiten distinguir entre aquellos riesgos de naturaleza Personal, Real o Patrimonial, lo que sigue la distinción clásica asociada a la naturaleza del derecho que se bus-

4 Baeza Pinto, Sergio. (1994). El seguro (Tercera Edición). Santiago, Chile: Editorial Jurídica. Págs. 63 y 64 . 
ca proteger $\stackrel{5}{5}$. Algunas pólizas hablan de coberturas "todo riesgo", pero es evidente que se trata de una descripción puramente caracterizadora que no necesariamente tiene una correlación literal, tal como algunos autores americanos se esfuerzan por aclarar ${ }^{6}$.

Esta visión tradicional nos permite distinguir también por magnitud, en términos de encontrarnos con riesgos puros y simples o riesgos catastróficos, por probabilidad, en términos de enfrentarnos a riesgos variables o invariables, o incluso por grado de variación, en términos de encontrarnos con eventos de magnitud constante, creciente, decreciente o estacionales ${ }^{\mathbb{P}}$.

Así las cosas, es natural poder afirmar que la doctrina tradicional ha hecho muy buenos esfuerzos por conceptualizar en toda su extensión lo que puede o no calificarse como riesgo asegurable, lo que ha sido resultado de acuciosos estudios de lo conocido o lo que podemos denominar industrias aseguradas tradicionales, como transporte, vida u otros riesgos masivos como salud o líneas financieras. Sin embargo, a nuestro parecer, estas categorías no son suficientes si lo que queremos en aproximarnos al entendimiento de riesgos nuevos, tanto en industrias tradicionales como no tradicionales.

Son estos nuevos riesgos los que calificamos como Riesgos Atípicos para distinguirlos de los típicos, es decir, aquellos ya conocidos y estudiados por la industria Aseguradora de manera acabada y que tienen procesos de suscripción y renovación más o menos mecánicos. En líneas generales, describimos los Riesgos Atípicos como como aquellos desconocidos, normalmente con escaso o nulo precedente de suscripción, vinculados a mercados o industrias en desarrollo y constante innovación y que, dadas esas características, poseen condiciones técnicas y prácticas eminentemente desconocidas para los Aseguradores tradicionales del mercado.

Califican como Riesgos Atípicos, por ejemplo, el proveedor de atmosferas controladas para carga perecible durante el transporte marítimo

5 CONTRERAS S., OSVALDO (2002) "El Contrato de Seguros" (Santiago, Editorial Jurídica de Chile), página 32 .

6 "All risk cover does not mean cover literally against all risks". Malcom, A. Clark. The law of insurance contracs, second edition. 1994. Lloyd's of London press ltd.

7 Ob. Cit. $\mathrm{N}^{\circ} 6$, Contreras, Pág. 33. 
o agricultor que busca proteger su siembra del daño que eventualmente pudiere derivar de daños climáticos imprevisibles, sin mencionar una serie de otros riesgos que derivan directa o indirectamente de la constante evolución tecnológica.

La noción propuesta involucra en su caracterización todos los elementos conocidos de los riesgos típicos (antes mencionados), pero agrega un elemento propio de la tecnología que es el dinamismo ${ }^{8}$. Tal como las industrias asociadas a la innovación, proponemos un concepto de riesgo dinámico, el que tendrá propiedades adaptables a la naturaleza del riesgo que estamos buscando transferir mediante un contrato de seguros 9 . Para entender qué implica en la práctica lo mencionado nos enfocaremos en dos procesos relevantes en la suscripción de un seguro: en primer término, la fase de descripción y delimitación del riesgo al momento de cotizar y suscribir una póliza, y luego desde la administración de siniestros. Sumado a lo anterior, incluiremos un análisis en contacto de la relación de consumo existente entre el Asegurado (contratante tomador) y Asegurador. En base a estas tres visiones prácticas fundamentaremos que para la Industria Aseguradora resulta relevante incorporar una visión dinámica de riesgo asegurable al momento de la contratación ya que aportará una herramienta de mejor administración de riesgos y posibilidades de desarrollar nuevos negocios en industrias emergentes, lo que permitirá sofisticar las actuales líneas de negocios no sólo desde lo comercial, sino también desde lo contractual, aportando un nuevo elemento en base al cual sustentar de manera eficaz y eficiente el sostenido crecimiento del sector.

\subsection{Desde la suscripción de riesgos}

Cuando el mercado Asegurador se enfrenta a un nuevo riesgo, sea que provenga de un industria tradicional o no tradicional, tiende naturalmente a actuar de manera proactiva, obviamente motivado por un elemento comercial. En este contexto, es común encontrar como solución de cobertura la aplicación

8 Siguiendo a Baeza Ovalle (2008) podríamos afirmar que la tecnología posee como características esenciales las siguientes: i. Acumulatividad; ii. Universalidad; iii. Dinamismo; iv. Carácter Social; v. Condición Ilimitada; y, vi. Transmisibilidad. BAEZA O., GONZALO (2008) "Tratado de Derecho Comercial", Tomo III. Legal Publishing, Santiago, Chile. Pp. 1644 y ss.

9 En esta línea de investigación: ZORNOSA P., HILDA (2009)"El Riesgo Asegurable y los riesgos Emergentes de las nuevas tecnologías". Revista de Derecho Privado. Universidad del Externado de Colombia. $N^{\circ} 17$, año 2009, pp. 141 a 173. 
extensiva de pólizas de Responsabilidad Civil, las que se adaptan mediante la incorporación de condicionados de aplicación a coberturas puramente financieras derivadas de la ocurrencia de aquel hecho nuevo, no conocido, pero calificado como Asegurable.

Comercialmente estas soluciones son aplicables y, desde la perspectiva del Asegurado que posee este riesgo atípico, probablemente sea una solución inmediata que cumpla con transferir a un tercero un riesgo que definitivamente no está dispuesto a tolerar autónomamente. Ahora bien, ¿Tiene esta decisión, basada inicialmente en aspectos comerciales o económicos, impacto a nivel del cumplimiento de las cargas o deberes del Asegurador y Asegurado?

A nivel del Declaración o Información oportuna, creemos que definir previo a la suscripción de un seguro si estamos o no frente a un riesgo atípico puede aportar, particularmente dado que las legislaciones contemporáneas de seguros incluyen deberes de sinceridad no sólo en la declaración de la naturaleza del riesgo sino también en la identificación de su potencial extensión ${ }^{10}$. Creemos que el vocablo "sinceridad" 11 hace referencia a un estándar de información mayor al habitualmente utilizando en la práctica y, particularmente respecto de los riesgos que hemos calificados como atípicos, se haría extensivo no sólo a aportar claridad respecto a la naturaleza del riesgo que se está buscando asegurar y/o la extensión o magnitud en caso de ocurrencia, sino también a la transmisión de herramientas de cuantificación, estudio o delimitación que permitan al potencial Asegurador identificar autónomamente si se trata de un riesgo asegurable o no.

Otro deber que cobra relevancia en esta perspectiva de análisis es el de No Agravación del riesgo. En este sentido, generalmente los cuerpos normativos regionales incluyen una mención a que será deber del Asegurado "informar al Asegurador los hechos o circunstancias que graven sustancialmente el riesgo Asegurado" $\underline{12}$, pero conceptualizar en los hechos qué implica este deber no

10 En Chile, a través de la Ley 20.667 promulgada el 9 de mayo de 2013, se incluyó en el art. 524 número 1 expresamente lo mencionado, además de identificar como otros deberes del asegurador el de no agravación del riesgo y el de oportuna información respecto de otros seguros existentes que pudieren involucrar el mismo interés asegurable.

11 En este sentido, en Chile, la Ley 20.667 vino a complementar la regulación existente en orden a incorporar nociones descriptivas derivadas del principio Uberrima Bona Fides, base sobre la cual se erige la confianza en la que se funda la transferencia de riesgos en el contrato de seguros. Detalles respecto de los aportes de esta Ley en CARVAJAL A., LORENA Y MAYER L., LAURA (2015) El Nuevo Fraude de Seguros. Artículo académico, Revista de Derecho de la Universidad Católica del Norte, Chile. Págs. 280 y ss.

12 Art. 526 del Código de Comercio de Chile, incorporado mediante la Ley 20.667 antes citada. 
es fácil desde la perspectiva del Asegurador, menos cuando estamos frente a un riesgo del que conoce más el Asegurado.

En esta fase, creemos que el deber de No Agravación no comienza con la ocurrencia del siniestro como tradicionalmente se entiende (y como el mismo inciso segundo del Art. 526 del Código de Comercio chileno proclama), sino que deviene de la delimitación que el Asegurado realice del riesgo previo a la suscripción, particularmente porque es el Asegurado o futuro tomador quien debe ser capaz de exponer al Asegurador todas las potenciales agravaciones a las que el riesgo que se busca asegurar está expuesto. De otro modo, si el Asegurador está frente a un riesgo asegurable (a priori) pero no conocido, ¿cómo podría realizar una correcta valoración?

En Chile la legislación a abordado esto. El actual art. 514 del Código de Comercio indica que la "propuesta" del seguro se debe contener "los antecedentes y circunstancias necesarios para apreciar la extensión de los riesgos". A partir de esto, la sana doctrina ha entendido que se da vida, de manera nítida, a la noción precontractual del Deber de Información que todo Asegurado diligente tiene. A su vez, mediante las leyes 20.555 y 20.667 se ha fomentado la delimitación de los deberes de otros auxiliares de la industria, lo que fue recogido por el actual Art. 529 número 1 del mismo Código, donde además de identificar como obligación del Asegurador la de indemnización oportuna, indica que en caso de ausencia de intermediador o corredor es responsable de "ofrecer las coberturas más convenientes" e incluso los hace responsable en caso de "errores y omisiones" que pudieren afectar al Asegurado ${ }^{13}$.

En nuestra perspectiva, creemos que el efecto precontractual no sólo es respecto del Deber de Información, sino también del de No Agravación, particularmente si es que el foco de la revisión está centrado en las nuevas industrias y los Riesgos Atípicos. Y esto deviene natural no sólo por ser el Asegurado o potencial tomador el único que maneje todas las variables del riesgo y sus factores de agravación, sino además porque el Asegurador está en una evidente desventaja al no tratarse de riesgos masivos ampliamente estudiados o conocidos por la Industria, justamente por ser un nuevas tipo de ocurrencias.

13 BARRIENTOS Z., MARCELO (2017) "Nuevos Deberes precontractuales de información en los certificados de cobertura provisorio, definitivo y la propuesta del contrato de seguro". Revista de Derecho, Universidad Católica del Norte, Sección Estudios, Año 22, N¹, 2015, pp. 65-144. (La Serena, Chile). 
Ahora bien, lo mencionado respecto del claro matiz precontractual de los Deberes de Información y No Agravación respecto del Asegurado también tiene un efecto en los Deberes del Asegurador. Así las cosas, lo natural es que el Asegurador responda por los riesgos descritos en la póliza y la excepción vendrá dada justamente por aquello que expresamente se excluya. Por tanto, frente a un riesgo atípico el Asegurador también tendrá un interés por conocer acabadamente la extensión de un riesgo previo a su suscripción. De hecho, se entiende que uno de los deberes del Asegurador, además de indemnizar el siniestro cubierto de acuerdo a la póliza, es el de oportuna y profesional asesoría al Asegurado, particularmente respecto de las coberturas ofrecidas lo que tiene directa relación con la profundidad que el Asegurador haga del riesgo que se busca asegurar.

Se podría afirmar que cuando la suscripción de un riesgo está intermediada por un Corredor de Seguros la intensidad del deber de correcta asesoría decae respecto del Asegurador, pero esto es relativo dado que a nivel de responsabilidad de los Corredores de Seguros existen estatutos bastante limitados ${ }^{14}$. En nuestra opinión se debe distinguir entre la responsabilidad que le es imputable frente a la intermediación de un riesgo conocido y uno no conocido, la que debiese ser menor a la responsabilidad que le cabría de cara a la falta de los deberes de asesoría profesional y oportuna de cara a $\mathrm{n}$ riesgo más bien tradicional (así como los de información o delimitación de un Riesgo típico respecto del Asegurado), pudiendo incluso extenderse una solidaridad si lo que buscamos es justamente evitar circunstancias de aprovechamiento coordinado o actitudes de defraudación.

En este punto, respecto del Riesgo Atípico, creemos que el intermediario tiene un deber de diligencia que no se agota simplemente en informar al cotizante o tomador acerca de las implicaciones de comportamientos reticentes o desleales durante las etapas de formación y ejecución del seguro, sino que debe participar activamente, mediante una asesoría profesional en la conceptualización del Riesgo Atípico y en

14 Para todas las legislaciones que no cuentan con estatutos de responsabilidad expresa respecto de estos agentes, pareciera que la solución inmediata es asignarles factores de apreciación de culpa (responsabilidad subjetiva) similares a la que se aplica a los otros profesionales, como la responsabilidad del Abogado o la del Médico (quienes manejan una particular lex artis) respecto del cliente que es una persona no capacitada o informada. Esto, sin perjuicio que el origen de la responsabilidad pueda ser contractual o extracontractual, dependiendo de la naturaleza del vínculo jurídico existente. 
la formulación de la descripción al Asegurador, algo mucho más activo que el rol que en la práctica terminan ejecutando.

En la práctica, la concreción funcional de estos deberes debería materializarse en esfuerzos de levantamiento de información más exhaustivos, distintos de los tradicionales formularios, y muy probablemente asociados a la aplicación de nuevas tecnologías. La práctica en otros sectores del Derecho donde la necesidad de contar con flujos de información relevantes puede aportar estrategias de obtención que la industria Aseguradora puede adoptar.

Por ejemplo, el creciente interés por instaurar mecanismos eficientes de prevención de fraudes ha devenido en el diseño de estrategias que permitan obtener información periódica sobre cómo los agentes de instituciones públicas o privadas perciben los cambios a nivel de clima laboral y cómo evoluciona la aversión o propensión a que ocurran actos potencialmente corruptos. Un centro de investigación de Holanda, en un estudio de reciente publicación, demuestra empíricamente que es posible mediante el seguimiento de las variaciones en las respuestas inferir la mayor o menor propensión de una organización a que ocurra un acto no deseado ${ }^{\frac{15}{5}}$.

Lo anterior, extrapolado a la industria Aseguradora, implicaría que un Asegurador de un riesgo atípico debería ser necesariamente capaz de darle seguimiento periódico al desarrollo del nuevo riesgo Asegurado buscando, al menos, ir internalizando por ejemplo (1) qué nivel de propensión existe respecto de la ocurrencia del riesgo Asegurado; (2) qué fundamentos técnicos, operativos o funcionales podría explicar esa potencial propensión o no la dicha ocurrencia; (3) si existe relación entre factores exógenos a la industria que influyan en la frecuencia o gravedad de la ocurrencia; o (4) si existen factores que el Asegurado maneje exclusivamente que influyan en la materialización del riesgo.

Tradicionalmente estos elementos o puntos de estudio los maneja el Asegurador internamente, es decir, son aspectos de control que no necesariamente implican seguimiento periódico a través de la declaración del Asegurado que está contratando el seguro. La clave entonces está en lo

15 GORSIRA, MADELIJNE; STEG, LINDA; DENKERS, ADRIAAN; AND HUISMAN, WIM (2017) Articulo académico. Administrative Sciences Jorurnal, N8, año 2018. Mdpi. 
siguiente: Cuando un Asegurador acepta asegurar un riesgo atípico debe transmitir al Asegurado la responsabilidad de continua información por un periodo de tiempo tal que permita internalizar todas las variables que involucre la ocurrencia de un siniestro. Esto implica que el nivel de cumplimiento del Deber de Información, desde la perspectiva del Asegurado, y de Asesoría Profesional, respecto del Asegurador o Intermediador, no sólo tiene una faz pre-contratual, sino que durante la misma vigencia contractual implica un nivel o grado de diligencia continuo y superior al tradicional.

\subsection{Desde la administración de siniestros}

En un escenario práctico, visto ex post la ocurrencia de un siniestro asociado a un Riesgo Atipico, también podemos visualizar efectos potencialmente negativos que debiésemos ser capaces de prever y mitigar a través de un uso preventivo de esta categoría y la noción precontractual de los deberes antes estudiados. Por ejemplo, se podría incluir expresamente como antecedente a solicitar por parte del liquidador nominado copia de aquellos antecedentes especialmente estudiados durante el proceso de suscripción de un Riesgo Atípico. Actualmente, en los hechos, muchas veces los Liquidadores o Ajustadores de pérdidas, particularmente los de Pólizas de Responsabilidad Civil, deben comenzar a recopilar antecedentes asociados a la operación del Asegurado como si el riesgo fuere completamente desconocido, tiempo que influye negativamente en los plazos de liquidación, y que obviamente se ven extendidos en desmedros de la gestión de este auxiliar del mercado. Por tanto, si el riesgo suscrito llegase al Liquidador calificado como Atípico, podría incluso incluir un nivel especial de información a solicitar, mitigando estas demoras, y aportando mayor contexto de cara a un siniestro.

Es evidente que lo mencionado puede tener un efecto aún de mayor relevancia, que es justamente la interpretación de la noción de riesgo asegurado que se incluye en la póliza ${ }^{16}$, labor que llega en múltiples oportunidades a manos del Liquidador sólo una vez ocurrido el siniestro, surgiendo en una etapa indeseada la necesidad de analizar la delimitación del Riesgo Asegurado.

16 En este sentido, VEIGA COPO indica que interpretar un seguro implica clarificar una serie de documentos, agregando que si se debe interpretar es "porque la aseguradora ha faltado a su deber de hablar claro (clare loqui)" lo que, en nuestra opinión, es un deber que encuentra origen incluso en lo previo a la suscripción, tal como hemos sostenido. Lo anterior en: VEIGA COPO, ABEL (2016) "Tratado del Contrato de Seguros". Editorial Thomson Reuters-Civitas. Madrid, España. Cap. VII, pp. 302 y ss. 


\subsection{El Asegurado con Consumidor: El caso chileno.}

En Chile, mediante la Ley 20.555 promulgada en diciembre de 2011, se estableció que los Seguros serán considerados como productos financieros y que todo contrato estandarizado, incluyendo los propios seguros, deben regirse también por la Ley 19.496 de Protección al Consumidor. Por tanto, existe norma expresa en la que encontramos la fuente de nuestro interés por revisar esta perspectiva de análisis.

En este mismo sentido, en 2013, se promulgó la Ley 20.667, norma que, tal como comentamos, vino a complementar lo anterior en orden a aportar una nueva regulación para el contrato de seguros, abandonando de manera definitiva las líneas de libertad contractual que el contrato de seguros tenía desde sus inicios, pasando a la noción activa de Deber de Información como elemento precontractual dados los actuales artículos $512,527 \mathrm{~N}^{\circ} 1$ y particularmente respecto del Art. 525 asociado a la declaración sobre el estado del riesgo, declaración que debe ser suficiente para "apreciar la extensión del riesgo", lo que contrario sensu implica que el Asegurador es quien se debe ocupar de hacer preguntas precisas, lo que implica necesariamente reconocer que para la industria aseguradora también existe un deber precontractual de correcta valoración del riesgo y asesoría, lo que encuentra su fundamento práctico en esta norma y otras asociadas a deberes de declaración del Asegurado.

Desde una perspectiva del Derecho del Consumo podemos encontrar también efectos prácticos que derivarían de asumir ex ante una noción dinámica de riesgo y, por cierto, de asumir la noción precontractual de las cargas del Asegurado y Asegurador. En esta línea, debemos tener presente que la relación que existe entre un Asegurador y un Asegurado es la propia de un Proveedor y un Consumidor y, en ese sentido, existe la relación de consumo que Chile establece como requisito formal de análisis el art. 3 de la Ley de Protección al Consumidor $\mathrm{N}^{\circ} 19.496$.

En términos generales, se entiende como consumidores aquellas personas naturales o jurídicas que adquieren o compran un bien o servicio mediante un acto jurídico oneroso o a quienes disfrutan o gozan de un producto, como el beneficiario de un contrato de seguros. Son consumidores, entonces, tanto personas naturales, como jurídicas, sean consumidores materiales o jurídicos propiamente tales ${ }^{17}$.

17 Nociones respecto de la evolución regulatoria y judicial del concepto de "Consumidor" y cómo ello 
En la relación Asegurador-Asegurado no sólo tenemos una relación consumidor-proveedor, sino que además nos encontramos frente a una materialización de la relación contractual que muy normalmente se produce a través de la contratación por adhesión, es decir, mediante un contrato (póliza) que no es libremente redactado o discutido, sino que se circunscribe a condicionados generales y particulares redactados de acuerdo a intereses previos a los del mismo tomador, y que están relacionados con los de la industria y cada Asegurador en particular. Así las cosas, incorporar sanciones en caso de incumplimiento u otras protecciones, desde la perspectiva del adherente (Asegurado), resulta complejo $\frac{18}{}$.

Es en el sentido expuesto que la regulación de consumo se presenta como un estatuto proteccionista que se establece en favor del consumidor. Sin embargo, en la Industria Aseguradora esto es relativo, y para entender el fondo de esta afirmación cobra valor definir qué nivel de profesionalismo posee el consumidor (en nuestro interés, Asegurado o contratante-tomador), lo que debe abordarse desde dos perspectivas: a) profesionalismo desde la perspectiva de la materia que maneja, es decir, desde el riesgo que administra (riesgo asegurable típico o atípico); y b) profesionalismo desde la perspectiva del entendimiento del seguro, desde una visión contractual y funcional.

Así las cosas, no basta definir en términos puros y simples al consumidor como aquel "no proveedor", sino que necesariamente debe realizarse un ejercicio adicional dado que, considerando la cada vez más nítida relación entre seguros y derecho del consumidor, cobra sentido práctico al menos desde dos perspectivas funcionales que son relevantes de considerar:

En primer término, un consumidor profesional desde las dos perspectivas antes mencionadas (desde el riesgo que administra y desde el entendimiento del seguro en tanto producto) es un potencial Asegurado

impacta en la noción actual de la relación de consumo en: BARRIENTOS, FRANCISCA (2017)

"La Evolución judicial del concepto de consumidor", artículo académico de iniciación proyecto FONDECYT N¹1140516. Documento académico, curso Derecho Civil, Universidad Diego Portales. Santiago, Chile.

18 La contratación por adhesión tiene un origen histórico que se funda no sólo en intereses corporativos, sino en fines funcionales y proteccionistas respecto del asegurado o tomador no profesional. Justamente en este sentido va el rol fiscalizador de organismos administrativos de supervisión. En este sentido, la Ley 19.496, en Chile, establece protecciones respecto a la redacción y contenido de este tipo de documentos (Art. 16 letra f y 17). TAPIA R., MAURICIO y VALDIVIA O., JOSE MIGUEL (2002) “Contrato por Adhesión: Ley 19.496”. Editorial Jurídica de Chile. Santiago, Chile. Pp 59 y ss. 
que rompe con la natural asimetría en el manejo de información que se asocia como intrínseca a las relaciones de consumo. Estos potenciales Asegurados necesariamente tendrán que convivir con una inversión en la carga de la prueba $\mathrm{o}$, al menos con una visión probatoria dinámica, lo que implicará no sólo profesionalizar la toma de seguro por un interés de cumplimiento de los deberes precontractuales sino además porque en caso buscar utilizar la regulación de consumo como defensa o estatuto protector deberá compartir el rol probatorio que naturalmente (en este ámbito) corresponde al proveedor.

Desde este primer término creemos que se configura una excepción o límite al Deber del Asegurador o intermediado de seguros (Corredor) respecto de la correcta delimitación y oportuna asesoría, particularmente dado que, frente a un Asegurado (contratante tomador) profesional en las dos perspectivas descritas, el Asegurador deberá compartir necesariamente de manera equitativa con la carga de dar contenido a la suficiencia que la declaración del riesgo Asegurado reclama. Y decimos "necesariamente" porque el Asegurado-tomador responsable y profesional debe ser capaz de reaccionar proveyendo incluso más información de la natural y obviamente necesaria en caso de estar buscando transferir un riesgo atípico, a diferencia de lo que ocurre en un riesgo tradicional donde los estándares de declaración y suficiencia son conocidos. Así las cosas, desde esta perspectiva, encontramos una ventaja para el Asegurador en la incorporación y reconocimiento expreso en los condicionados de cobertura (y pólizas) de la noción dinámica de riesgo que proponemos.

En segundo término, desde la perspectiva de los Aseguradores, deben considerar que regulaciones como las de consumo están cada vez más relacionadas con la industria Aseguradora, no sólo por la natural asimetría de información que existe entre los Asegurados y Aseguradores, sino porque la diversificación de riesgos, la aparición de nuevos actores e industrias relevantes, y la innovación como motor del emprendimiento, ha robustecido un target de consumidores que, aun cuando son personas jurídicas, si son calificables como consumidores y, derivado directo de ello, el Asegurador se podrá encontrar ofreciendo coberturas a riesgos atípicos estableciendo garantías que pueden ser excesivamente onerosas, cláusulas abusivas, entre otras condiciones, todo lo que para industrias tradicionales era tolerado pero que en nuevos contextos amerita matices. 
Así las cosas, internalizar la noción de riesgos dinámicos de cara a la gestión de riesgos atípicos o no tradicionales no sólo será una herramienta efectiva de suscripción, ni representa únicamente un elemento que permite fundamentar en términos prácticos la noción precontractual de ciertos deberes o cargas, sino que además permite prever variaciones en estatutos infraccionales conexos de eminente relevancia, como la regulación de consumo discutida, extiendo efectos prácticos en campos o contextos que no guardan relación directa y regular con la Industria Asegurada, pero que con el devenir de los años y el fortalecimiento de los estatutos de protección para relaciones contractuales asimétricas irán cobrando vigor.

\section{APROXIMACIÓN PRÁCTICA: LA AGROINDUSTRIA Y EL TRANSPORTE}

Los agroseguros inicialmente se circunscribían a Seguros Agrícolas o de Cosecha que eran más bien mecanismos de asignación o distribución de subsidios de origen gubernamental dirigido a un sector productivo que al 1910-1920 era débil pero esencial para la sociedad: la Industria Agrícola. Así las cosas, podemos afirmar los orígenes del Seguro Agrícola datan del año 1917, cuando frente a múltiples problemas asociados a riesgos climáticos la industria Aseguradora europea comenzó a diseñar estructuras de cobertura. Formalmente, podemos datar el nacimiento de esta figura de transferencia en el año 1919, cuando se crea en España la Mutualidad Nacional del Seguro Agropecuario $\underline{19}$.

En sus orígenes estos seguros no sólo eran de naturaleza asistencial, sino que se reducían exclusivamente a cubrir pérdidas financieras derivadas de un evento que dañara la cosecha, sea por clima y otros eventos, como incendio, inundación o sequía. Esta perspectiva fue en base a la cual la Industria Aseguradora comenzó a ofrecer programas de cobertura. Sin embargo, con el tiempo, la Agroindustria comenzó a implementar tecnologías a sus procesos productivos, lo que ha permitido profundizar el estudio

19 CALATAYUD P., ENDINA y ESCRIBANO P., SANTIAGO (2008) "La Importancia de los Seguros Agrarios como motor del desarrollo rural y su necesidad de adaptación a los cultivos sociales". Estudio disponible en Ministerio de Agricultura, Pesca y Alimentación de España, Biblioteca on-line: www.map ama.gob.es/ es/.../Cal atayud_Segu ros_tcm30-103390 .pdf.pp pp. 4 y ss. 
de las casuísticas propias de los agro-riesgos. Hoy podemos afirmar que el riesgo agrícola (en tanto cosecha, siguiendo la original nomenclatura) tiene al menos 3 perspectivas de análisis, implicando 3 o más nociones de riesgos que originalmente se circunscribían a una sola cobertura.

En primer término, existen riesgos de campo asociados directamente a técnicas de cultivo y precosecha. En esta fase, los riesgos de suelo y técnicas de cultivo se han visto ampliamente desarrollados y estudiados por la industria de agroquímicos y los estudios genéticos que la agronomía a desarrollado los últimos años. Así, podemos afirmar que es posible identificar, previo a la plantación, riesgos de pérdida incluso por factores extrínsecos al cultivo, tal como la composición salina del suelo o la contaminación potencial por adherencia de agentes patógenos ambientales al futuro fruto ${ }^{20}$.

En segundo término, existen riesgos de producción y almacenamiento. Acá la fase temporal de análisis o revisión es distinta a la de la fase anterior, estamos en una fase que media entre la plantación o siembra y la guarda o almacenaje. Lo relevante es que la tecnología ha puesto a disposición de la agroindustria tecnologías de cultivo basadas no sólo en lo químico, sino también en términos de monitoreo metabólico, permitiendo incluso mitigar o corregir durante el crecimiento o desarrollo del fruto factores como color, sabor o resistencia. Esto se ve potenciado por técnicas de almacenaje basados en frío, lo que se desarrolló fuertemente durante los 70, y que se complementa actualmente con aplicación de atmósferas modificadas. En esta fase se desarrollaban gran parte de los riesgos que finalmente se indemnizaban por pólizas de Seguro Agrícola generándose una distorsión que finalmente llevó a limitar el acceso a esta forma de subsidio estatal en prácticamente todas las naciones donde existía $\mathrm{a}^{21}$.

20 CISNEROS-ZEBALLOS, LUIS (2017) La Nanotecnología para la prevención y descontaminación de patógenos en productos frescos. Ponencia, IX Congreso Iberoamericano de tecnología, postcosecha y agroexportaciones. Santiago, Chile. Diciembre, 2017. Facultad de Ciencias Agronómicas de la Universidad de Chile en conjunto a INIA (Centro de Investigaciones Agropecuarias).

21 En este mismo sentido, ya el año 1989 la FAO (Food and Agriculture Organizaton of the United Nations) reconocía como necesario realizar una "clara distinción de objetivos para evitar la confusión que se produce cuando se atribuye metas (al seguro agrícola) que no puede alcanzar", lo que justamente hacia referencia a que la naturaleza indemnizatoria que se le buscaba asignar al seguro agrícola difería de su inicial objetivo. Cita contenida en p. 8 AVALOS, L., ALIDE (1989) "Riesgos en la Agricultura y agroindustria, y modalidades de seguro". IICA, San José (Costa Rica). Programa de Análisis y Panificación de la política Agraria (México, D.F., CEMLA 
Finalmente, existen riesgos de distribución asociados a la comercialización y logística. En esta fase el riesgo agrícola a implicado múltiples desafíos para la Industria del Transporte, particularmente por tratarse muchas veces de productos altamente sensibles no sólo a factores como la temperatura, sino a las condiciones estiba, los tiempos de tránsito y las atmósferas a las que se somete la carga durante el transporte. Acá el riesgo, desde la perspectiva del transporte, también ha variado aceleradamente los últimos años, incorporando nuevos elementos de potencial agravación y nuevos actores a una cadena logística que, con la incorporación de conceptos como el de transporte multimodal. Lo anterior, sumado a nuevas tecnologías en contenedores reefer o refrigerados producidos por empresas distintas de las navieras o transportistas terrestres en base a tecnologías que integran control de temperatura y atmósfera, y nuevas técnicas de recubrimiento de pallets en base a bolsas de poliuretano que permiten intercambio gaseoso, hacen del transporte de fruta una fase técnica relevante en el mantenimiento de condiciones óptimas para la carga, lo que por cierto complejiza la cadena de pesquisa de responsabilidades.

Estas tres fases de visualización de un riesgo permiten soslayar dificultades con las que la industria Aseguradora vivió por años, particularmente respecto de (i) lo problemático de cuantificar y/o valorizar las pérdidas financieras asociadas a una producción dañada; (ii) la ausencia de estudios que permitan ofrecer soluciones a riesgos de siembra no conocidos y que aportan con segregar riesgos de campo de riesgos de cosecha; y (iii) la ausencia de estudios instrumentales respecto de riesgos climáticos no estacionales.

Hoy estas fases de análisis de riesgo permiten ofrecer programas de cobertura diferidos y generar una correcta asignación de costos, lo que no sólo es atractivo desde el punto de vista económico y los intereses del tomador, sino que es eficiente desde lo retributivo en perspectivas de la industria Aseguradora, incorporando nuevos riesgos que a su vez implica aceptar e internalizar la responsabilidad de terceros proveedores que han surgido sólo en los últimos años como consecuencia de los desarrollos tecnológicos propios de una industria distinta de la Aseguradora. Por tanto, conceptualizar correctamente un riesgo, aplicando en el análisis nuevas tecnologías, se traduce directamente en beneficios de suscripción y transferencia de riesgos para el Asegurado, y mayores oportunidades de 
negocios para la Industria Aseguradora. Esto hoy se traduce en Seguros Agrícolas que cubren rendimientos óptimos anuales, Seguros Multiriesgos Agropecuarios o Agroseguros Integrales, todos distintos de los Seguros Generales de Responsabilidad que la industria Aseguradora ha diseñado para fases de cosecha, acopio, almacenaje, selección y packing, distribución, estiba y transporte.

Lo expuesto es una muestra práctica respecto de cómo a evolucionado en los últimos 80 años una industria tradicional (y aceleradamente los últimos 20), presentando hoy, gracias a la tecnología e innovación, nuevas configuraciones de riesgos asegurables en base a distintas formas de aproximación. Lo clave viene dado por el dinamismo que dijimos toda industria posee. Frente a esa realidad, no es insensato pensar que las mencionadas industrias continúen incorporando nuevos riesgos y nuevas industrias asegurables conexas a las principales. Sólo a modo de ejemplo: hoy existen investigaciones en torno al Ozono como elemento incorporable a las atmosferas al momento de almacenar o transportar fruta, además de técnicas del desarrollo de composiciones químicas de manejo y control de nuevas enfermedades o patologías no conocidas antes, esto sin mencionar la aplicación de nanopartículas de cobre en la epidermis de diversas variedades frutales en fase de selección en packing, entre otros.

Es a este acelerado desarrollo de las Industrias Aseguradas tradicionales (y asegurables no tradicionales) a lo que los Aseguradores deben hacer frente sofisticando sus técnicas de estudio y valoración de riesgos. En este orden de ideas, creemos que incorporar una noción dinámica de Riesgo Asegurable, definiendo márgenes de transformación tolerable, permite aportar una herramienta contractual eficiente a la hora de aceptar incorporar riesgos no conocidos como asegurables, permitiendo así ir internalizando en la industria información que permita, ex ante, aportar mayores elementos descriptivos de valoración y, finalmente, adoptar mejores medidas de aprehensión de técnicas de suscripción y mayores posibilidades de negocios, teniendo como efecto jurídico la extensión de los deberes y cargas a una perspectiva precontractual, según se estudió en el acápite anterior. 


\section{PERSPECTIVAS REGULATORIAS PARA OBTENER VENTAJAS DE LAS OPORTUNIDADES}

Lo regulatorio y las nuevas tecnologías deben verse apoyadas por una visión dinámica de riesgo que permita mayores libertades contractuales. Un esfuerzo normativo, en términos de incorporar a nivel legislativo la noción de riesgo asegurable tradicional y no tradicional (o atípico) claramente implicaría años de debate respecto del fundamento jurídico y funcional de dicha disquisición. Sin embargo, desde lo comercial, creemos que sí hay fuertes beneficios, sin considerar que desde lo jurídico tiene implicancias relevantes, particularmente dado que la noción de riesgo atípico constituye una prueba fáctica o empírica de la relevancia de aceptar nociones precontractuales de los deberes o cargas del Asegurador y el Asegurado.

Así la cosas, creemos que la Industria Aseguradora tiene posibilidades de aprovechar las ventajas de una noción dinámica de riesgo si es que incorpora su utilidad funcional desde lo regulatorio. En general, los Seguros se regulan mediante organismos públicos desconcentrados y descentralizados, es decir, dependientes indirectamente de la administración central del Estado. Esto se traduce, por ejemplo, en que la Comisión para el Mercado Financiero, ex Superintendencia de Valores y Seguros en Chile $\underline{22}$, pueda emitir NCG (Normas de Carácter General) mediante las cuales incluya instrucciones o modificaciones generales respecto de la industria Aseguradora, además de poder fiscalizar y controlar el cumplimiento de las directrices que emite para todo el mercado.

22 No es objeto de la presente investigación determinar la naturaleza de este tipo de instituciones, sin embargo, hacemos presente la existencia de contingentes debates respecto de la justificación de su existencia y del ejercicio de un Poder Publico que pareciera excesivo a la luz de las facultades y atribuciones que poseen. En nuestra opinión, las Superintendencias u Organismos Reguladores no transgreden principios constitucionales como el de la Liberta Económica, sino que materializa una faz de control que siempre y en todo caso debe encontrar como límite la Moral, el Orden Público y la Seguridad Nacional, tal como lo establece el art. 19 N²1 de la Constitución Política de Chile. Sin perjuicio de lo dicho, distintos han sido los autores que han analizado en detalle, desde la perspectiva crítica, la existencia de este tipo de instituciones en el contexto regulatorio, en esa línea: CORDERO V. LUIS Y GARCÍA J. F. (2012 [“Elementos para la discusión de agencias independientes en Chile. El caso de las Superintendencias"] Documento presentado en el tercer encuentro anual de la Sociedad de Políticas Públicas); GARCÍA J. F. Y VERDUGO, S. (2010 ["De las Superintendencias a las Agencias reguladoras independientes en Chile: aspectos constitucionales y de diseño regulatorio". Actualidad Jurídica UDD, año XI, n²2]); DÍAZ DE VALDEZ J. (2010 ["Anomalías constitucionales de las Superintendencias: un diagnóstico". Estudios Constitucionales Universidad de Talca, año 8, $n^{\circ} 1, p$. 249 - 282] https://scielo. conicyt.c 1/pdf/estcons t/v8n1/ art09.pdf); GARCÍA, J.F. (2009 [“Inflación de las Superintendencias: un diagnóstico crítico". Actualidad Jurídica UDD, n 19, Pp. 327 - 372]). 
Desde nuestra perspectiva, estos Organismos Reguladores deben propender naturalmente a fomentar la existencia de todas condiciones técnicas y profesionales que aseguren mayor inversión en el sector en base a mayores certezas. Así las cosas, creemos que la fase de control regulatorio de la Industria Aseguradora, en tanto Industria Regulada, es la llave que permite incorporar a las eficiencias de mercado conceptos modernos como los de Riesgo Atípico u otros que permitan poner a disposición de los Aseguradores herramientas efectivas de delimitación y transferencia de nuevos riesgos. Por tanto, en nuestra opinión, la primera y esencial fase de internalización de esto nuevos elementos descriptivos debe venir necesariamente dado por el reconocimiento expreso, desde lo regulatorio, de la necesidad de distinguir entre riesgos tradicionales y no tradicionales, aceptando expresamente la existencia de una fase precontractual de los deberes conocidos, incorporando así un eslabón regulatorio que fomente el profesionalismo y estudio técnico-casuístico de los riesgos no sólo en los Aseguradores y Asegurados sino también en otros agentes involucrados en la transferencia y gestión de riesgos, tales como los Corredores de Seguros y los Ajustadores de Pérdidas.

\section{CONCLUSIONES}

Los efectos prácticos que derivan de una conceptualización dinámica del riesgo asegurable aportan matices funcionales que muy probablemente inyecten dinamismo a la industria Aseguradora. Así las cosas, serian al menos 4 las fases de gestión en las que una correcta aprehensión del riesgo Asegurado nos podrá dar las certezas que la industria reclama día a día.

En primer término, durante la fase de delimitación del riesgo para efectos de suscripción, cobrará sentido tener sentada las bases no sólo respecto de la frecuencia con la que ocurre aquel riesgo que se quiere transferir, si no, además, la naturaleza de la ocurrencia, puesto que de ello deviene si estemos frente a un riesgo conocido o a un riesgo calificable como atípico, con las particularidades que indicamos ello tenía. Es justamente en esta etapa donde los deberes de información veraz y 
oportuna, la no agravasión y asesoramiento independiente, profesional e integral, cobran especial valor en la figura del Asegurador y, extensivamente, del Corredor de Seguros como intermediario y auxiliar del mercado Asegurador.

Enseguida, luego de identificado el riesgo asegurable y delimitada su extensión, se podrá salir al mercado en búsqueda de uno o más productos diseñados para la transferencia de dicha ocurrencia. Lo vital es identificar que cuando estemos frente a un riesgo asegurable conocido o típico, sabremos ex ante que muy probablemente el mercado ya cuente con diseños de cobertura operando.

Sin embargo, cuando notemos que estamos frente a un riesgo atípico, en tanto riesgo asegurable pero desconocido, tendremos luces respecto a que muy probablemente el mercado hará múltiples esfuerzos por generar soluciones taylor made, y es en ese escenario donde la naturaleza precontractual de los deberes del Asegurado cobran capital relevancia, dado que muchas veces, como en la agroindustria planteada en ejemplo, tendremos Asegurados que no sólo sean conocedores de sus riesgos, sino además únicos agentes que capturen esa naturaleza de contingencia en sus operaciones. Pensamos naturalmente en industrias vinculadas a la ciencia y tecnología, mercados donde la innovación acelerada y absoluta confidencialidad, se contraponen a las ideas de conocimiento suficiente e información completa que el mercado Asegurador pretende. Por tanto, aquí la noción dinámica de riesgo analizada será una solución práctica (pero no necesariamente económica en términos de prima) a la hora de limitar la extensión del riesgo transferido y limitar la responsabilidad del tomador (futuro Asegurado) ante problemas de cobertura derivadas de ausencia de suficiencia en la información provista al estudiar el riesgo.

En tercer lugar, y como consecuencia directa de lo planteado, frente a una hipótesis de ocurrencia asociado a un riesgo poco frecuente los ajustadores de pérdidas o liquidadores también necesitarán disponer de aquella información recabada al momento de suscribir el riesgo. Lo importante es que las minutas o certificados de coberturas de riesgos abiertamente declarados como atípicos deberían, como recomendación, incluir un análisis técnico de las potenciales ocurrencias, sus hipotéticas extensiones en términos de daños $\mathrm{y}$, evidentemente, ejemplos o pruebas de manifestaciones que permitan al 
ajustador tomar esa información y contrastarla con la realidad del siniestro en estudio. Es aquí donde la claridad de la información obtenida y la suficiencia en la delimitación del riesgo atípico podrán ser la clave entre un seguro que responda eficiente y eficazmente frente a la ocurrencia, y uno que simplemente funciona mientras no se le reclama cobertura.

Finalmente, tener claridad respecto a reglas de modificación o transformación de riesgos ayuda a internalizar ex ante costos económicos asociados a dichos cambios, lo que permite generar programas de cobertura de renovación automática con márgenes de primas autoajustables en función de la valoración de cambio que las partes hayan acordado del riesgo. Como se demostró respecto de los riesgos agrícolas, esto hoy es posible, y las nuevas tecnologías son la clave en estos futuros desarrollos, por lo que los futuros análisis de continuidad frente a este tipo de riesgos (los atípicos) debiesen tender a ser tan automáticos como ocurre hoy con riesgos masivos o affinity. Esta será una de las claves que permita poner a disposición del mercado Asegurador una herramienta efectiva a la hora de buscar sostener el crecimiento que al día de hoy a experimentado.

\section{BIBLIOGRAFÍA}

AVALOS, L., ALIDE (1989) "Riesgos en la Agricultura y agroindustria, y modalidades de seguro". IICA, San José (Costa Rica). Programa de Análisis y Panificación de la política Agraria (México, D.F., CEMLA

BAEZA O., GONZALO (2008) “Tratado de Derecho Comercial”, Tomo III. Legal Publishing, Santiago, Chile. Pp. 1644 y ss.

BAEZA P., SERGIO (1994) “El Seguro”. (Santiago, Editorial Jurídica, Tercera Edición).

BARRIENTOS, FRANCISCA (2017) “La Evolución judicial del concepto de consumidor", artículo académico de iniciación proyecto FONDECYT $\mathrm{N}^{\circ} 11140516$. Documento académico, curso Derecho Civil, Universidad Diego Portales. Santiago, Chile. 
CONTRERAS S., OSVALDO (2002) "El Contrato de Seguros" (Santiago, Editorial Jurídica de Chile)

BARRIENTOS Z., MARCELO (2017) "Nuevos Deberes precontractuales de información en los certificados de cobertura provisorio, definitivo y la propuesta del contrato de seguro". Revista de Derecho, Universidad Católica del Norte, Sección Estudios, Año 22, N¹, 2015, pp. 65-144. (La Serena, Chile).

CALATAYUD P., ENDINA y ESCRIBANO P., SANTIAGO (2008) "La Importancia de los Seguros Agrarios como motor del desarrollo rural y su necesidad de adaptación a los cultivos sociales". Estudio disponible en Ministerio de Agricultura, Pesca y Alimentación de España, Biblioteca on-line: www.mapa ma.gob.es/ es/.../Calatayud_Seguros_t cm30-103390.pdf .pp pp. 4 y ss.

CARVAJAL A., LORENA Y MAYER L., LAURA (2015) El Nuevo Fraude de Seguros. Artículo académico, Revista de Derecho de la Universidad Católica del Norte, Chile. Págs. 280 y ss.

CISNEROS-ZEBALLOS, LUIS (2017) La Nanotecnología para la prevención y descontaminación de patógenos en productos frescos. Ponencia, IX Congreso Iberoamericano de tecnología, postcosecha y agroexportaciones. Santiago, Chile. Diciembre, 2017. Facultad de Ciencias Agronómicas de la Universidad de Chile en conjunto a INIA (Centro de Investigaciones Agropecuarias).

GORSIRA, MADELIJNE; STEG, LINDA; DENKERS, ADRIAAN; AND HUISMAN, WIM (2017) Articulo académico. Administrative Sciences Jorurnal, N8, año 2018. Mdpi.

MALCON, CLARK (1994): "The law of insurance contracts" (London, Lloyd's of London press 1td, Second Edition).

TAPIA R., MAURICIO y VALDIVIA O., JOSE MIGUEL (2002) “Contrato por Adhesión: Ley 19.496”. Editorial Jurídica de Chile. Santiago, Chile. Pp 59 y ss. 
VEIGA COPO, ABEL (2016) “Tratado del Contrato de Seguros”. Editorial Thomson Reuters-Civitas. Madrid, España.

ZORNOSA P., HILDA (2009)"El Riesgo Asegurable y los riesgos Emergentes de las nuevas tecnologías". Revista de Derecho Privado. Universidad del Externado de Colombia. N 17, año 2009, pp. 141 a 173.

Bibliografía de consulta general

BARRIENTOS C., FRANCISCA (2013) "Una Mirada al silencio y la aceptación en los contratos por adhesión con consumidores a partir del caso Cencosud". Cuadernos de análisis jurídico, Colección de Derecho Privado VIII, Ediciones Universidad Diego Portales. Santiago, Chile.

BARRIENTOS Z. MARCELO (2015) “El deber precontractual de información en el contrato de seguro, un producto financiero y de consumo. estudio de sus fuentes". Revista Chilena de Derecho, Vol. 42 N², pp. 423 - 451. Santiago, Chile.

CONTRERAS S., OSVALDO (2005) "Derecho de Seguros" (Santiago, Editorial Thomson Reuters, Chile) 